\title{
Visual Social Publications in the Newspapers of Greek Primary Schools: A Semiotic Analysis
}

\author{
Lina P. Valsamidou \\ Communication \& Journalism, Open University of Cyprus, M.sc. in Cultural Studies, M.sc. \\ in Gender Studies, Xatzimaloussi1, 59200, Naoussa, Greece \\ E-mail: pvalsamidou@gmail.com
}

Accepted: May 23, 2013 Published: June 25, 2013

Doi:10.5296/jsr.v4i2.3645 URL: http://dx.doi.org/10.5296/jsr.v4i2.3645

\begin{abstract}
In the present study we investigate, record and discuss icons with a social content, their type, their signifieds and ideological significations, wishing to extract useful conclusions regarding the use of icons in school newspapers as vehicles of social messages. The research material comprises in total 252 images with a social content found in the columns of school newspapers, whereas the collection of the sample was based on the study of 64 school newspaper issues coming from 32 titles of primary school newspapers from all over Greece that were published in 2004-2006.

All in all, it appears that social iconic publications create the editors' vivid interest, as they find their way mostly in the inside pages of newspapers. The analysis of the icons as to their signifieds places emphasis on the dominant ideological forms: the signifieds of historic anniversaries, school life and environmental education come before the others, which in turn suggests the dominant ideological trends, history-school-environment/ecology: a triptych that emerges through the social-iconic choices of those involved in publishing school newspapers.
\end{abstract}

Keywords: visual social publications, school newspapers, semiotic analysis, students-journalists

\section{Introduction}

Recent years have known the dynamic development of a new "iconology", a new theory of images known as "visual theory" which practically constitutes an extension of iconology as defined by Panofsky (1991) only that it expands to all visual arts and the new forms of the technological icon. According to Jenks (1995) an icon is the eye of the mind, it is the subjective notion formed in the mind as a result of sensory stimuli. According to this view, an icon is identified with the representations and notions that are formed through diverse and complicated perceptions of various sensory stimuli.

According to Arnheim (1969), an image or visual-representational sign may be used 
for three different functions: as a "sign", as a "picture" or as a "symbol". A "sign" is an image that stands for a particular content (referent), without reflecting its characteristics visually, as a letter of the alphabet for example. A "picture" is an image (visual-representational sign) that renders the object (referent), as for example the visual image of a mountain or its portrayal with a triangle. A visual sign has a lower level of abstraction than the referent. A picture always states the visual qualities of things and it is always the image that shares a visible resemblance with the object it refers to. A "symbol" is a visual-representational sign that portrays a thing (referent) at a lower level of abstractness than is the thing (referent) itself, like for instance a triangle that serves as a symbol of equality. Arnheim (1969:12-13) states that "signs", symbols and pictures are three functions of an image, not three different types and their perception with one or another function depends on the way they are used, thus introducing the reader's ability in the interpretation of "signs".

Icons, according to Llorens (1979), are a means to visual representation. The term "icon" refers to the faithful depiction or schematic representation of reality, all types of painting, photography, designs, sketches, films, videotapes, even drawings produced by computers. Therefore, an icon in every form, as accumulation of meaning and as a means of communication, provides the visual communication with multiple possibilities due to the aesthetic codes and the divergence between the aesthetic codes of the transmitter and the receiver.

As proposed by Mitzroeff (1999:3-5), the turn to image is an effort to bridge "the gap between the wealth of visual experience in postmodern culture and the ability to analyze that observation", whereas the visual culture does not depend on pictures themselves, but on the modern tendency to picture or visualize existence. Barthes (1988) stresses that all iconic messages develop in a direct and obvious manner a complementary message apart from the analogical content (scene, object, landscape), which is what is usually called style of the reproduction. It is a second notion, whose signifier is a certain "handling" of the image owed to the action of the creator, and whose signified, whether aesthetic or ideological, refers to a certain "culture" of the society that receives the message.

Vryzas (1990) notes that although an image tends to appear as a simple and innocent reproduction of the real that is revealed immediately and is easily understood by everyone, yet it is not as perspicuous and candid as it seems, because an image of the reality is not the reality on the image, but the reality through the image: an image does not simply represent the real but it also transforms it while it locates only a few aspects of the real. Furthermore, an image constitutes a "writing" that, based on a code, organizes messages that are more polysemous and less imperative than those of language.

A school newspaper constitutes a multimodal product of pupils' communication in which they act as editors/transmitters and readers/receivers at the same time. It is also an agreement between children/editors and teachers/animators of the school edition. For Freinet (1977), typography and school newspapers were an essential point in his pedagogical proposal and he recommended the process of working in a printing establishment and the production of a school newspaper already from kindergarten school. A newspaper with the children's writings, designs and pictures selected democratically after a pupils' voting was regarded by the French pedagogue as a set of dominant interests for pupils and its mission in 
the scholastic and broader community/society was considered to bestow a maximum of tension to the desire to be heard at a distance (Freinet, 1977:49), which is essential for children.

In this context, school newspapers constitute the tribune and the means whereby pupil journalists and animating educators use news, their reports and their pictures to highlight what they regard as worthy of being published, or bequeathed to the wider audience, while they constitute a semiotic text that features and places emphasis on major school issues and the way to approach them.

\section{Purpose}

In the current study we investigate, record and analyze icons with a social content, their type, their signifieds and ideological significations wishing to extract helpful conclusions regarding the use of icons in school newspapers as carriers of social messages.

In a school newspaper pupils act as publishers - editors - photographers - designers at the same time. The icons they use carry signifieds/symbols/signs, since the icon as a photograph, drawing, sketch, design, visual material, or static image refers to an image and can be used as a sign, a picture or a symbol (Arnheim, 1969: 8, 12-13).

\section{Material}

Our research material comprises in total 252 icons with a social content that are found in school newspaper columns. The recording of the material was based on the study of 64 school newspaper issues that come from 32 newspaper titles of primary schools from all over Greece which were published in 2004-2006 (Appendix A). We randomly selected two issues from each newspaper that were published in the above period and we recorded the iconic social publications both of the front and the inside pages.

\section{Methodology}

Nowadays, the term semiotics is widely used in the scientific field of cultural studies and the most common brief definition is "the study of signs". It involves not only the study of what we call "signs" in everyday language, but also of every thing that "stands for" something else. In semiotics, signs involve words, images, sounds, gestures, practices and objects that are studied as a part of a sign system. Semioticians maintain that signs relate to their signifieds through socially acquired conventions, their function is on one hand to persuade and on the other hand to refer to and they do no simply convey meanings, but they also constitute the means whereby meanings are formed (Chandler, 1994).

Semiotics is based on the structuralistic view that the signs of conceptualization depend on and are defined by the relationship between them (Connel \& Mills, 1985: 33), while according to Seiter (1992:31) semiotics studies both the way in which signs relate and the rules that govern their use; consequently, when semiotics poses questions, it is more interested in how meaning is formed rather than the content of meaning itself. In our research 


\section{Macrothink}

Journal of Sociological Research

ISSN 1948-5468

2013, Vol. 4, No.2

for the analysis of the visual material we use Kress and van Leeuwen's "Grammar of the Visual Design" (1996), a methodology based on the theory of Systemic Functional Grammar developed by M.A.K. Halliday (1994). According to the model of Gunther Kress \& Theo van Leeuwen we can classify the iconic publications at the level of social semiotics: that means we are interested in the social context in which these iconic publications have been chosen and published. In this orientation we focus on the signifieds of the icons and the references of their content.

The purpose of this study is to analyse icons with a social content in school newspapers and for this we have chosen semiotic analysis: "a semiotic analysis analyses the various signs thoroughly, trying to define the structure and locate possible meanings" (Mc Quarrie \& Glen 1992).

\subsection{Unit of Recording and Categories/ Sample documentation}

The unit of recording in our sample was the iconic publication. We formulated the following table for the analysis of the iconic social publications:

1. Icon sequence number: the sequence number of the icon is logged.

2. Icon page: the page of the publication icon is recorded.

3. Number of iconographers: the number of the iconographer of the publication icon is registered, where it is mentioned of course.

4. Boys: the number of boy iconographers/photographers of the icon is recorded.

5. Girls: the number of girl iconographers/photographers of the icon is registered.

6. School class: the class of the iconographers/photographers of the icon is logged.

7. Type of icon: the type of the icon is recorded. We detected 9 types:

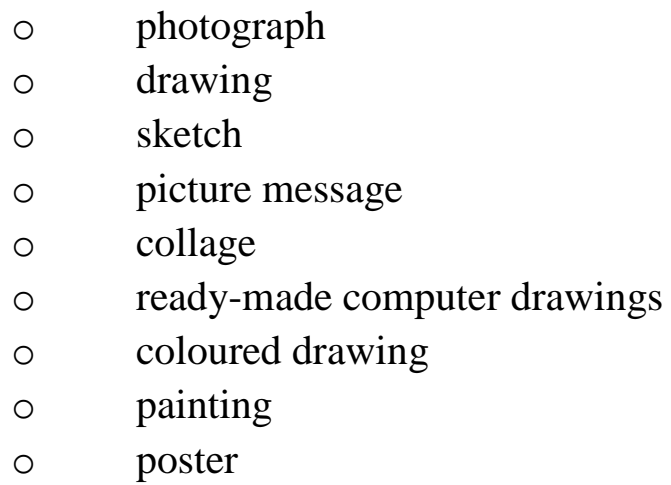

8. Icon colour: in this field the colour is registered in two categories:

○ black and white

- coloured

9. Dominant icon colour: the dominant colour of the icon is logged. As dominant colour we define the one that is projected more intensely on the icon and it is immediately imprinted in our memory as prevalent. Ten diverse categories are established:

o azure-blue

$\circ$ green

o red

o yellow

o brown 


$\begin{array}{ll}\circ & \text { pink } \\ \bigcirc & \text { white } \\ \bigcirc & \text { grey } \\ \bigcirc & \text { purple } \\ \bigcirc & \text { black }\end{array}$

10. Icon size: the size of the icon is recorded. Four sizes are located:

a) full-page

b) large - it covers half of the page

c) medium - it covers $1 / 4$ of the page

d) small - it is smaller than $1 / 4$ of the page

11. Icon position on the page: the position of the icon on the page is registered. Ten categories on this field are determined:

$\begin{array}{ll}\circ & \text { top } \\ \circ & \text { bottom } \\ \circ & \text { right } \\ \circ & \text { left } \\ \circ & \text { top right } \\ \circ & \text { bottom right } \\ \circ & \text { top left } \\ \circ & \text { bottom left } \\ \circ & \text { center } \\ \circ & \text { full-page }\end{array}$

The value of this information according to the grammar of the visual design at the level of textual metafunction - which is related to the arrangement of the icons on the page and the projection of particular elements of the composition - focuses on the "given" cognitive material which is presented on the left part of the design, the "new" material is on the right part, everything that is found at the upper part constitute the ideal, "what it could be", those found at the base are the real, that is objectively given facts, "they that are", whereas the core of information is stressed at the center (Kress \& van Leeuwen, 1996: 119 -158, Baldry \& Thibault 2006: 73 - 78, 94 - 97).

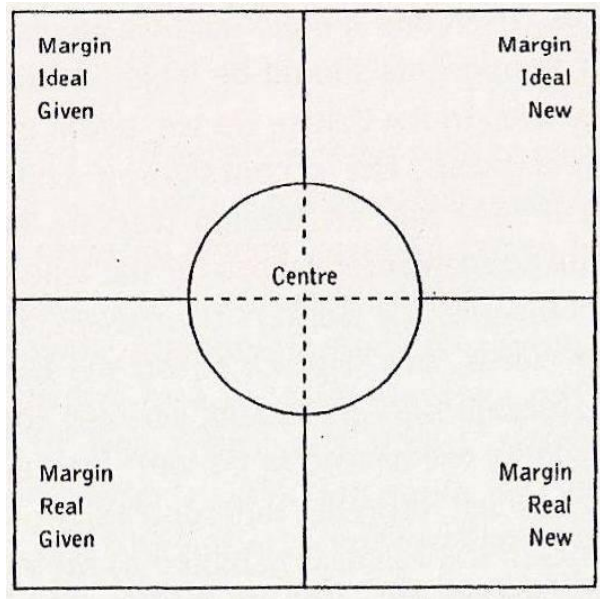


Figure 1.Source: Kress \& Van Leeuwen, 1996: 208

12. Icon signifieds: we located meanings that are projected through the icon that accompanies the verbal publication. We detected representations that are classified in 17 categories at the level of the content:

○ history and historical anniversary

$\circ \quad$ handicap, handicap and society, handicap and athletics

o school life

- environment, environmental education

○ interculturalism

- athletics

○ history of education, education and gender, reading pleasure

○ tradition, religious tradition and Greek culture

- childhood and interpersonal relationships

- Mass Media, mass culture, technology

$\circ \quad$ health education and road safety

○ politics, political education, democracy

$\circ \quad$ childhood values (friendship, love, peace, offering, rights, play)

o season

○ community

- economy and professions

- museum education

\section{Analysis}

The recording of icons in social publications led to the formation of table 1 , as to the page of the icon. It is inferred that the largest amount of icons is presented on the third page of the newspaper at $15,8 \%$, followed by the second page at a percentage of $13,1 \%$ whereas the fourth page comes at a narrow difference of $12,3 \%$, while the front page claims the fourth position on the table at a rate of $11,9 \%$.

Table 1: Iconic social publications per newspaper page

\begin{tabular}{|l|l|l|}
\hline Icons & & \multicolumn{2}{|l|}{} \\
\hline Icon page & $n$ & $\%$ \\
\hline 1 & 30 & 11,90 \\
\hline 2 & 33 & 13,10 \\
\hline 3 & 40 & 15,88 \\
\hline 4 & 31 & 12,30 \\
\hline 5 & 24 & 9,52 \\
\hline 6 & 19 & 7,54 \\
\hline 7 & 16 & 6,35 \\
\hline
\end{tabular}




\begin{tabular}{|l|l|l|}
\hline 8 & 13 & 5,15 \\
\hline 9 & 6 & 2,38 \\
\hline 10 & 8 & 3,17 \\
\hline 11 & 5 & 1,98 \\
\hline 12 & 6 & 2,38 \\
\hline 13 & 6 & 2,38 \\
\hline 15 & 2 & 0,80 \\
\hline 16 & 2 & 0,80 \\
\hline 17 & 2 & 0,80 \\
\hline 19 & 1 & 0,39 \\
\hline 20 & 2 & 0,80 \\
\hline 22 & 2 & 0,80 \\
\hline 24 & 4 & 1,58 \\
\hline Amount of icons & 252 & 100,00 \\
\hline
\end{tabular}

The analysis of the icons as to the number and gender of the iconographers led to the compilation of table 2, whereby it is confirmed that these data are indicated in 39 icons; in particular, 38 icons $(97,4 \%)$ have one iconographer and one icon $(2,5 \%)$ has two. From these, $76,9 \%$ (30 icons) are made by girls and only 23,07\% (9 icons) are made by boys. It is more than evident that girl iconographers deliver an overwhelming predominance, against boys that registered a limited percentage.

Table 2: Iconographers' number and gender

\begin{tabular}{|l|l|l|l|l|l|}
\hline \multicolumn{2}{|l|}{ Icons } & & & & Icons \\
\hline $\begin{array}{l}\text { Number of } \\
\text { iconographers }\end{array}$ & $\mathrm{n}$ & $\%$ & Gender & $\mathrm{n}$ & $\%$ \\
\hline 1 & 38 & 97,44 & Boys & 9 & 23,07 \\
\hline 2 & 1 & 2,56 & Girls & 30 & 76,93 \\
\hline
\end{tabular}

The analysis of the icons regarding the iconographers' school grade contributed to the composition of table 3 , the study of leads to the conclusion that the 6th grade iconographers hold a steady lead over those from the other grades, as 41,6\% come from the 6th grade, $19,4 \%$ from the 5th grade, whereas $16,6 \%$ is from the 4th grade of Primary school. The 6th grade pupils' lead is conspicuous both in illustrating and editing the publications.

Table 3: Iconographers' school grade

\begin{tabular}{|l|l|l|}
\hline \multicolumn{2}{|l|}{ Icons } \\
\hline Grade & $\mathrm{n}$ & $\%$ \\
\hline
\end{tabular}




\begin{tabular}{|l|l|l|} 
1st grade & 2 & 5,55 \\
\hline 2nd grade & 1 & 2,78 \\
\hline 3rd grade & 5 & 13,89 \\
\hline 4th grade & 6 & 16,66 \\
\hline 5th grade & 7 & 19,44 \\
\hline 6th grade & 15 & 41,68 \\
\hline Total & 36 & 100 \\
\hline
\end{tabular}

The analysis of our sample as regards to the type of icon resulted in the creation of table 4, where we notice the overwhelming lead of photographs $(60,7 \%)$ in the preferences of editors and animator teachers of the school newspapers over the other types of icons. At a 12,3\% we recorded ready-made computer drawings that appear to assume their position in the illustration preferences and practices of the managers of the school newspaper, drawings delivered a $11,5 \%$ percent, sketches received $7,1 \%$, picture messages generated a 3,5\%, while the other types such as paintings and coloured drawings have a limited presence. Collage and posters have a scarce percentage.

Table 4: Type of icon

\begin{tabular}{|l|l|l|}
\hline Type of icon & $\mathrm{n}$ & $\%$ \\
\hline photograph & 153 & 60,71 \\
\hline drawing & 29 & 11,50 \\
\hline sketch & 18 & 7,14 \\
\hline picture message & 9 & 3,58 \\
\hline collage & 2 & 0,80 \\
\hline $\begin{array}{l}\text { ready-made } \\
\text { computer drawing }\end{array}$ & 31 & 12,30 \\
\hline coloured drawing & 4 & 1,59 \\
\hline painting & 5 & 1,99 \\
\hline poster & 1 & 0,39 \\
\hline Total & 252 & 100 \\
\hline
\end{tabular}

The analysis of the sample icons concerning the colour and the dominant colour resulted in the creation of table 5. We registered 175 black and white icons $(69,4 \%)$ and 77 coloured ones $(30,5 \%)$. A noticeable trait is the editors' favourite practice of preferring black and white icons to the coloured ones. What conduces more to this of course is the precedence of photographs previously recorded, but also the fact that most newspapers are printed in black and white in order to reduce the printing cost, or they keep only a few coloured pages and mainly the front page, again for the purpose of compressing the printing cost. However, it was possible to log the dominant colour in the 77 coloured icons. Azure-blue, a colour that is connected with tranquility, maintains a clear lead (28,5\%), followed by green $(14,2 \%)-$ the colour that Kandinsky regarded as the most calmative there is (Kandinsky, 1981:107) - and grey $(14,2 \%$ ), red comes next at $12,9 \%$ (it is regarded as the colour that influences people's 


\section{Macrothink}

behaviour the most), whereas yellow and brown logged a 10,3\%. Black, white and pink generated $2,6 \%$ and purple delivered $1,3 \%$.

Table 5: Colour and dominant colour of the icons

\begin{tabular}{|l|l|l|}
\hline Colour & $\mathrm{n}$ & $\%$ \\
\hline Black and white & 175 & 69,44 \\
\hline coloured & 77 & 30,56 \\
\hline Dominant colour & $\mathrm{n}$ & $\%$ \\
\hline azure-blue & 22 & 28,57 \\
\hline green & 11 & 14,29 \\
\hline red & 10 & 12,99 \\
\hline yellow & 8 & 10,38 \\
\hline brown & 8 & 10,38 \\
\hline pink & 2 & 2,60 \\
\hline white & 2 & 2,60 \\
\hline grey & 11 & 14,29 \\
\hline purple & 1 & 1,30 \\
\hline black & 2 & 2,60 \\
\hline
\end{tabular}

Colour constitutes a dynamic element that may function at two levels in static (but also motion) images (Sivropoulou, 2003:150-151):

a) at the cognitive level, colour conveys information either on clearly descriptive terms, for example the tree leaves that change colour in autumn, or on symbolic terms, as for instance in the case of traffic lights and

b) at the emotional level, colour functions on the basis of psychological connections, arousing dispositions and emotions, while it may affects us physically and psychologically.

At the newspaper icon, colour functions mainly at the emotional level. Consequently, what is defined as a dominant colour is not necessarily the one that presents a quantitative prevalence at the newspaper icon, but the one that visually challenges our interest and is directly imprinted on our memory. Following the colour chart according to temperature, as defined by Kandinsky (1981: 100-101), we classified all 77 coloured icons in three categories: cool colours, warm colours, no colour).

Table 6: Distribution of colour icons according to colour temperature

\begin{tabular}{|l|l|l|l|l|l|}
\cline { 2 - 4 } \multicolumn{1}{c|}{} & $\begin{array}{l}\text { Dominant } \\
\text { colour }\end{array}$ & Frequency & Percentage \% & $\begin{array}{l}\text { Overall } \\
\text { frequency }\end{array}$ & $\begin{array}{l}\text { Overall } \\
\text { percentage \% }\end{array}$ \\
\hline \multirow{4}{*}{$\begin{array}{l}\text { Cool } \\
\text { colours }\end{array}$} & azure-blue & 22 & \multicolumn{2}{|c|}{28,57} & \\
\cline { 2 - 4 } & purple & 1 & 1,30 & \\
\cline { 2 - 4 } Warm & green & 11 & 14,29 & 34 & 44,16 \\
\hline
\end{tabular}




\begin{tabular}{|l|l|l|l|l|l|}
\hline \multirow{5}{*}{ colours } & yellow & 8 & 10,38 & \\
& brown & 8 & 10,38 & \\
& pink & 2 & 2,60 & \\
& white & 2 & 2,60 & & \\
\hline \multirow{4}{*}{$\begin{array}{l}\text { No } \\
\text { colour }\end{array}$} & black & 2 & 2,60 & & \\
\hline Trey & 11 & 14,29 & 15 & 19,49 \\
\hline
\end{tabular}

Close attention to table 6 reveals a precedence of cool colours, although warm colours follow at a narrow difference, whereas the No colour category is less used by the school newspaper iconographers/photographers.

The analysis of the material as to the size of the icons resulted in the formulation of table 7 , which demonstrates that the vast majority of the icons $(89,2 \%)$ is of small size, medium-sized icons (1/4 of the page) following at a wide difference of 7,9\% and large-sized icons at $2,7 \%$, while there are no full-page images.

Table 7: Size of icons

\begin{tabular}{|l|l|l|}
\hline Size & $\mathrm{n}$ & $\%$ \\
\hline Full-page & 0 & 0 \\
\hline Large & 7 & 2,77 \\
\hline Medium & 20 & 7,94 \\
\hline Small & 225 & 89,29 \\
\hline Total & 252 & 100,00 \\
\hline
\end{tabular}

Where the position of the icons on the page is concerned, the analysis of our sample generated table 8 , which displays an advantage of $40,4 \%$ regarding icons on the right in the vertical division of the page, whereas in the horizontal division it is the icons on the top that lead by a percentage of $40,06 \%$. When the page is divided in quadrants, the icons at the top right quadrant take precedence by $19,8 \%$. As noted above, the informational value according to the grammar of visual design (Kress \& Van Leeuwen, 1996) at the level of textual metafunction focuses on the "given/established" cognitive material which is placed on the left side of the layout, the "new" is on the right, the elements placed on the upper section constitute the ideal, "what might be", those at the bottom are the real or objectively presented facts, "what is", whereas the nucleus of information is highlighted at the centre.

Table 8: Arrangement of icons on the page

\begin{tabular}{|l|l|l|l|l|l|l|l|l|}
\hline $\begin{array}{l}\text { Placement } \\
\text { of icons on } \\
\text { the page }\end{array}$ & $\mathrm{n}$ & $\%$ & $\begin{array}{l}\text { Placement/ } \\
\text { horizontal } \\
\text { division }\end{array}$ & $\mathrm{n}$ & $\%$ & $\begin{array}{l}\text { Placement/ } \\
\text { vertical } \\
\text { division }\end{array}$ & $\mathrm{n}$ & $\%$ \\
\hline Top & 24 & 9,52 & Top & 24 & 9,52 & Top right & 50 & 19,85 \\
\hline Bottom & 29 & 11,51 & Top right & 50 & 19,85 & $\begin{array}{l}\text { Bottom } \\
\text { right }\end{array}$ & 38 & 15,08 \\
\hline
\end{tabular}




\section{MInstitute Macrothink $_{\text {Int }}$}

\begin{tabular}{|l|l|l|l|l|l|l|l|l|} 
Top right & 50 & 19,85 & Top left & 37 & 14,69 & Right & 14 & 5,55 \\
\hline $\begin{array}{l}\text { Bottom } \\
\text { right }\end{array}$ & 38 & 15,08 & Top/Total & 111 & 44,06 & Right/Total & 102 & 40,48 \\
\hline Top left & 37 & 14,69 & Bottom & 29 & 11,51 & Top left & 37 & 14,69 \\
\hline Bottom left & 24 & 9,52 & Bottom right & 38 & 15,08 & Bottom left & 24 & 9,52 \\
\hline Centre & 21 & 8,33 & Bottom left & 24 & 9,52 & Left & 15 & 5,95 \\
\hline Left & 15 & 5,95 & Bottom/Total & 91 & 36,11 & Left/Total & 76 & 30,16 \\
\hline Right & 14 & 5,55 & Centre & 21 & 8,33 & Centre & 21 & 8,33 \\
\hline Total & 252 & 100 & \multicolumn{7}{|l|}{} & & \\
\cline { 1 - 5 }
\end{tabular}

The analysis of the icons at the level of denotation led to the following results, where their signifieds are evident and are defined as meanings in the manner that they are projected in the icons and at content level:

- $\quad$ signifieds of history, with 44 content references $(17,46 \%)$ to historic anniversaries, the German occupation and world war II, the Greek revolution of 1821 and the Athens Polytechnic uprising in 1973

- $\quad$ signifieds of school life, with 38 content references $(15,07 \%)$ to students' activities at school, in class, in excursions

- $\quad$ signifieds of environment, with 29 content references $(11,50 \%)$ to environmental issues, recycling, protection of the environment, flora and fauna

- $\quad$ signifieds of childhood and interpersonal relationships, with 24 content references $(9,52 \%)$ to children's faces, to images of family and friends

- $\quad$ signifieds of health and road safety education with 19 content references $(7,53 \%)$ to issues of health and road conduct, consumerism, obesity, alcohol, nutrition and food

- $\quad$ signifieds of tradition, with 18 content references and a percentage of 7,14\% to religious tradition, Greek and folk culture

- $\quad$ signifieds of politics, political education, democracy with 13 content references and a percentage of $5,15 \%$ to political persons, the regime, elections and the parliament

- $\quad$ signifieds of Media/mass culture and technology with 11 content references and a percentage of $4,37 \%$ to television, mobile phones, new communication technologies

- $\quad$ signifieds of childhood values with 11 content references and a percentage of $4,37 \%$ to friendship, love and peace

- $\quad$ signifieds of disability also with 11 content references and a percentage of $4,37 \%$ to disability and sports, disability and society, accessibility of the disabled persons

- $\quad$ signifieds of interculturalism with 11 content references and a percentage of $4,37 \%$ to children from other cultures, immigrants, foreigners

- $\quad$ signifieds of museum education with 7 content references and a percentage of $2,77 \%$ to museums, centres of environmental education, aquariums

- $\quad$ signifieds of athletics with 5 content references and a percentage of $1,99 \%$ to violence in sports, fair play, hooliganism

- $\quad$ signifieds of history of education, education and gender, reading for pleasure with 5 content references $(1,99 \%)$ to book reading in pupils of earlier times 
- $\quad$ signifieds of economy and professions with 2 content references $(0,80 \%)$ to professions and professionals, to economy and money

- $\quad$ signifieds of seasons with 2 content references $(0,80 \%)$ to seasons and weather conditions

- $\quad$ signifieds of community also with 2 content references $(0,80 \%)$ to works that were completed in the local community.

\section{Discussion}

All in all, it appears that social iconic publications create the editors' vivid interest, as they find their way mostly in the inside pages of newspapers. They are mainly of a small size, for the most part they are illustrated by girls of the 6th grade and they primarily belong to the type of the black and white photograph. Semiotically they appear at the lower section of the layout which denotes the real, but also on the right part which signifies the "new".

The analysis of the icons as to their signifieds places emphasis on the dominant ideological forms: the signifieds of historic anniversaries, school life and environmental education come before the others, which in turn suggests the dominant ideological trends, history-school-environment/ecology: a triptych that emerges through the social-iconic choices of those involved in publishing school newspapers. A triptych that conveys the implicit orientation of the educational system at the level of Greek primary schools and rises through the study of the dominant icons in the school newspaper columns.

It is without a doubt that a school newspaper constitutes a semiotic text that conveys meanings and explicit or implicit notions and the language of the icons, the "visual language" (Fiske, 1982:97) functions metaphorically and symbolically. The social symbols of the history of the Greek nation, school life and ecology that outnumber the others in the pages of school newspapers clearly emphasize the goal as well as the result of the educational policy of the Greek public school, while they allow the emergence of dominant ideological forms that traverse school life and school communicative practice.

\section{References}

Arnheim, R. (1969). Visual Thinking. Berkeley: University of California Press.

Baldry, A. P. \& Thibault, P. J. (2006). Multimodal Transcription and Text Analysis. London: Equinox.

Barthes, R. (1988). Image - Music - Text. (Preface by G. Veltsos, translated by G. Spanos). Athens: Plethron (in greek).

Vryzas, K. (1990). Mass Media and Education. Modern Education vol. 51, 77-89 (in greek). Chandler, D. (1994). Semiotics for Beginners, from www.aber.ac.uk/ dgc /semiotic.html [18/05/05].

Connel, I. \& Mills, A. (1985). Text, Discourse and Mass Communication. In van Dijk, T. A. (ed.). Discourse and Communication: New approaches to the Analyses of Mass Media Discourse and Communication. Research in Text Theory Series. Vol. 10, 26-43. Berlin: de Gruyter.

Fiske, J. (1982). Introduction to Communication Studies. London: Routledge. 


\section{I Macrothink}

Freinet, C. (1977). The School of the People. (Translated by K. Denaxa-Venieratou). Athens: Odysseas (in greek).

Halliday, M. A. K. (1994). An Introduction to Functional Grammar. (2nd edition). London: Arnold.

Jenks, C. (1995). The Centrality of the Eye in Western Culture. In Jenks, C. (eds). Visual Culture. 1-25, London: Routledge.

Kandinsky, W. (1981). For Intellectual in the Art. (Translated by M. Parasxos). Athens: Nefeli (in greek).

Kress, G \& van Leeuwen, T. (1996): Reading Images: The Grammar of Visual Design. London: Routledge

Llorens, T. (1979). Notes for a definition of aesthetic Semiosis. The Hague: Mouton.

Mc Quarrie, E. F. \& Glen, M. D. (1992). On Resonance: A Critical Pluralistic Inquiry into Advertising Rhetoric. Journal of Consumer Research,19(2), 180-197.

Mirzoeff, N. (1999). An Introduction to Visual Culture. London: Routledge.

Panofsky, E. (1991). Studies in Iconology. (Translated by A. Pappas). Athens: Nefeli (in greek).

Seiter, E. (1992). Semiotics, Structuralism and Television. Allen, R. C. (ed.). Channels of Discourse, Reassembled: Television and Contemporary Critisism. $2^{\text {nd }}$ Edition, 31-66. London: Routledge.

Sivropoulou, R. (2003). A Journey in the World of Illustrated Short Stories. Athens: Metaichmio (in greek).

\section{Appendix}

Appendix 1. Greek Primary School newspaper titles

1) Ponies with... pens, Interscholastic pupil newspaper of the 5th district of Primary Education of the Larissa prefecture

2) Chirps of Aerino, 4th Primary school of Feres -Aerino/4th Kindergarten of Feres -Aerino, EUBOIA

3)Velo Pupils' Brushwork, Primary school of Velo, CORINTHIA

4) Cats with petals, 2nd Primary school of Lixouri, CEPHALLONIA

5) Communication, 2nd Primary school of Skydra, PELLA

6) The pen of the Fifth, 5th Primary school of Giannitsa, PELLA

7) Our small nest, Newspaper of the 4th grade, 8th Primary school of CHIOS

8) Sunbeam, 5th Primary school of CHIOS

9) Chalk, 6th Primary school of ZAKYNTHOS

10) Pupils' pens, 2nd of LARISSA

11) School beehive, 1st Primary school of Vrondados CHIOS

12) Pupils' speech, Primary school of Rizo, PELLA

13) Pupil's world, Primary school of Neo Petritsi, SERRES

14) In a few words, 4th Primary school of Naoussa, IMATHIA

15) Through children's eyes, 2nd Primary school of Nemea, CORINTHIA

16) The world through children's eyes, 6th Intercultural and fulltime Primary school of Eleftherio Kordeliou, THESSALONIKI

17) The pupils' world of the 7th, 7th Primary school of CHIOS

18) Young journalists, Primary school of Vochaiko, CORINTHIA 


\section{Macrothink}

19) Children's inquires, 6th Primary school of Rethymno, CRETE

20) Children's voices of Stimaga, Primary school of Stimaga, CORINTHIA

21) Children's Typography, Experimental and fulltime Primary school of Anatoliko, THESSALONIKI

22) Pegassos, Primary school of Archaia CORINTH

23) Early school bulletins, Primary school of Afratio, EUBOIA

24) School pen, 2nd Primary school of Pefka, THESSALONIKI

25) The little bees, Primary school of Megali Panagia, CHALKIDIKI

26) The Milakia, Primary school of MILOS

27) The children of Kingfisher, Primary school of Vrachati, CORINTH

28) The desk, 10th Primary school of Evosmos, THESSALONIKI

29) The little room, 2nd Primary school of Rethymno, CRETE

30) Flutters, 1st Experimental Primary school of FLORINA

31) Flutters, 1st Primary school of CORINTH

32) Flutters, Primary school of Thymiana, CHIOS

Appendix 2. Visual material 


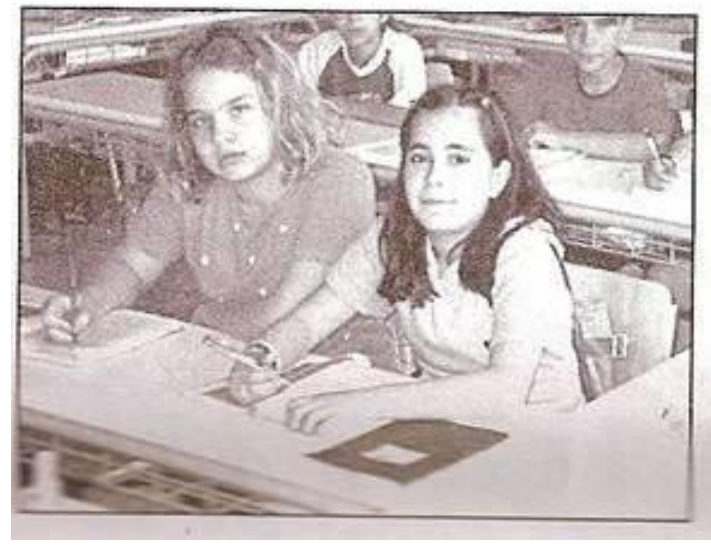

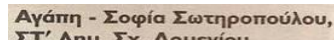
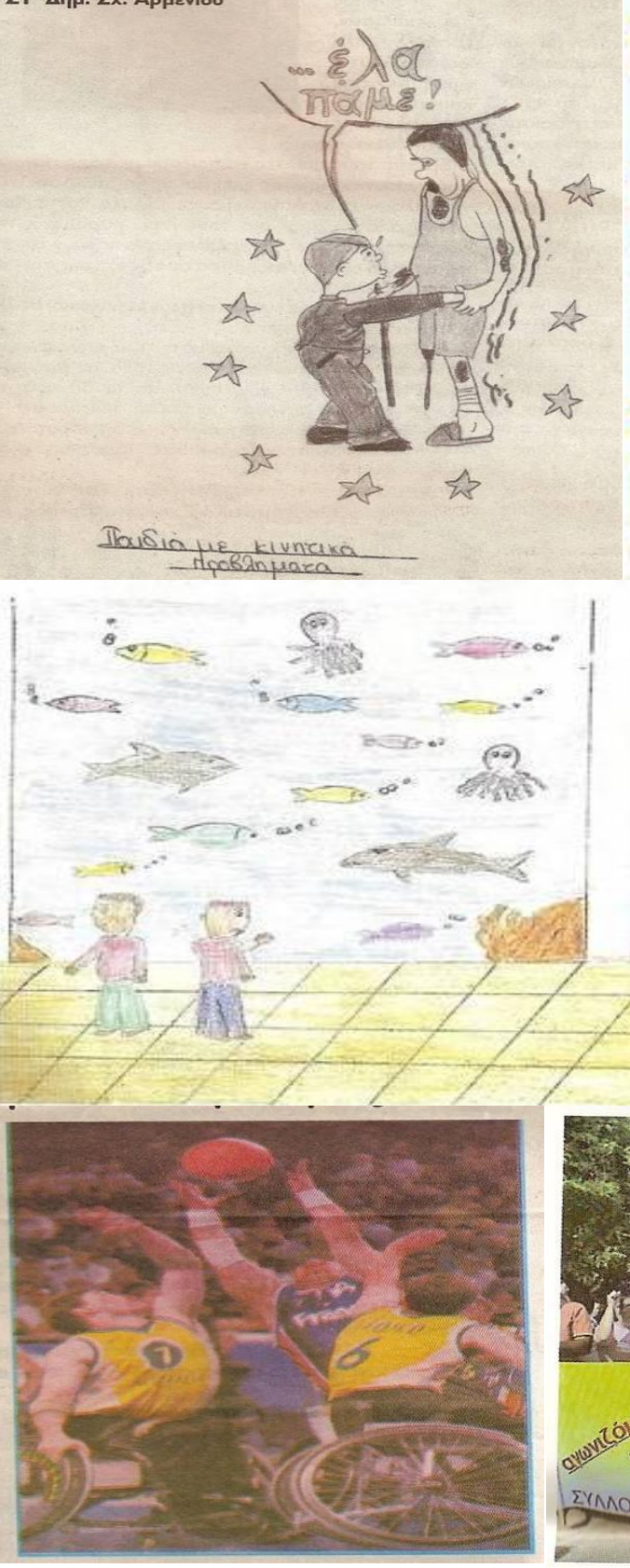

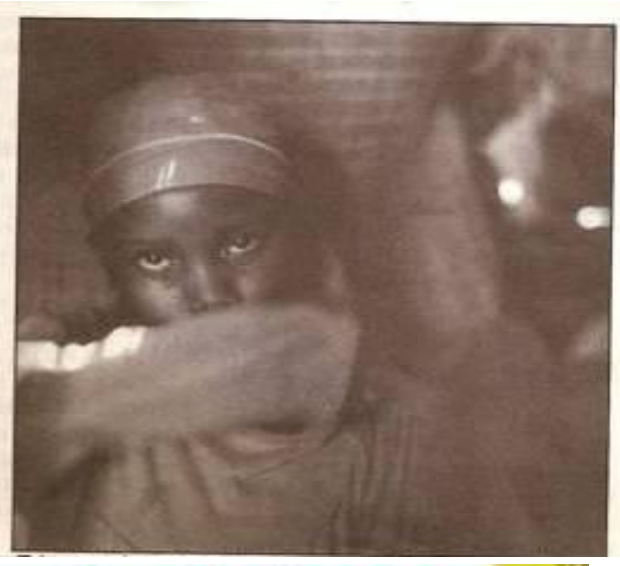

T เ

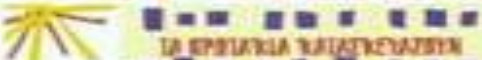

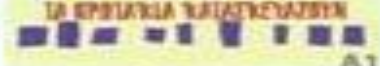
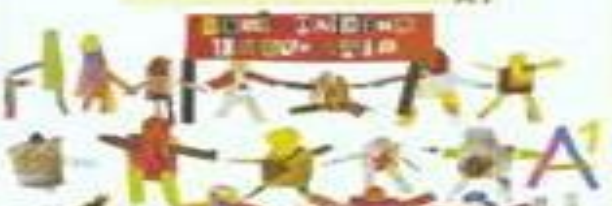

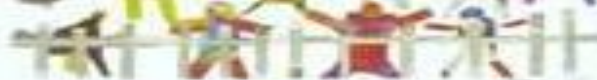
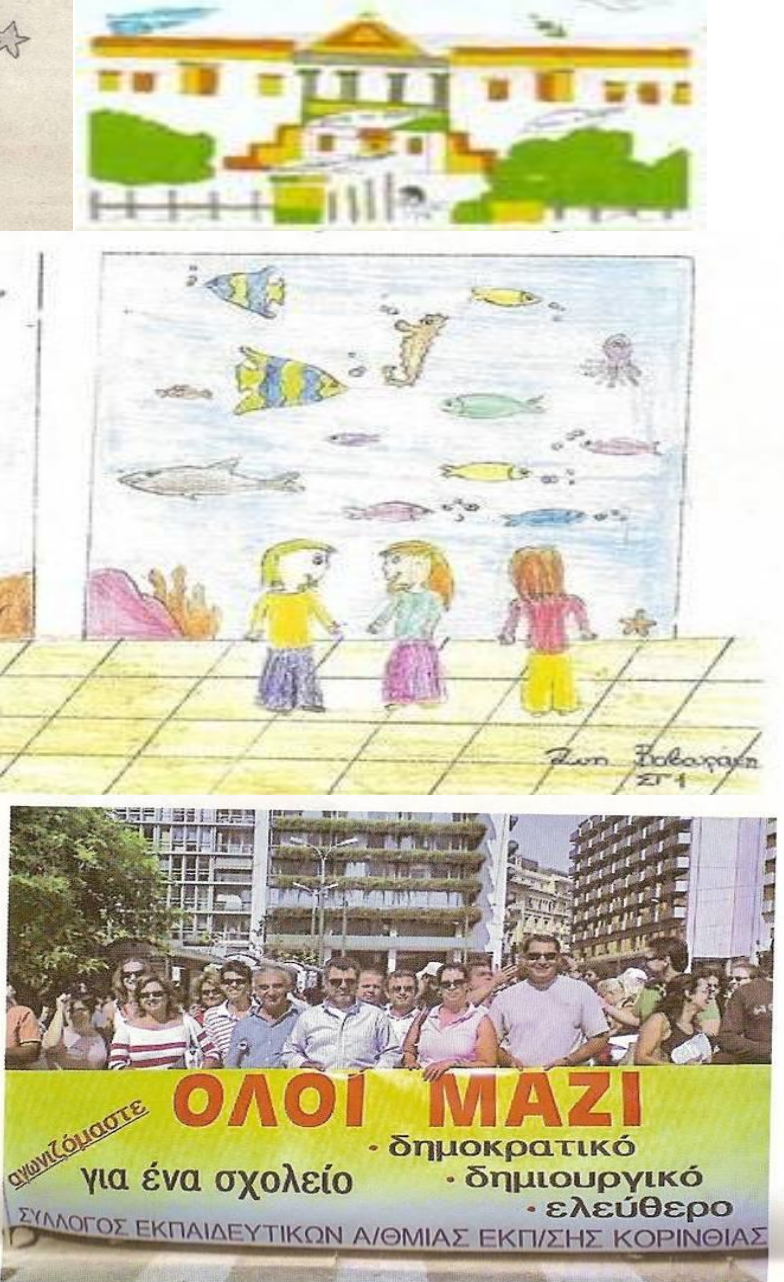

othink.org/jsr 